\title{
Treatment of congenital clubfoot and its outcome in Mekelle hospital, Tigray, Ethiopia
}

\author{
Hafte Teklay, Yared Asmare, Manay Kifle, Mebrahtom Abraha, \\ Zeray Baraki, Berihu Fissiha, Gebremedhin Hagos, Dejen Gezehegn
}

\begin{abstract}
Aims: Congenital clubfoot is a deformity of the lower extremity manifested by foot adduction/ inversion, cavus and plantar flexion. Its incidence varies within $0.5-7$ per 1000 live births worldwide. Genetic predisposition, environmental factors and combination of them are assumed to have etiological factor. A number of trials have been made to cure clubfoot long years ago. But none of them was as effective as
\end{abstract}

Hafte Teklay ${ }^{1}$, Yared Asmare ${ }^{2}$, Manay Kifle ${ }^{3}$, Mebrahtom Abraha $^{4}$, Zeray Baraki ${ }^{5}$, Berihu Fissiha ${ }^{6}$, Gebremedhin Hagos $^{7}$, Dejen Gezehegn ${ }^{8}$

Affiliations: 'Lecturer of Human Anatomy, Department of Biomedical Sciences, College of health Sciences and Referral hospital Aksum University, Aksum, Ethiopia; ${ }^{2}$ Lecturer of Human Anatomy, Department of Human Anatomy, College of Medicine and Health Science, University of Gondar, Gondar, Ethiopia; ${ }^{3}$ Lecturer of Public Health, Department of Public Health, College of Health Sciences and Referral Hospital Aksum University, Aksum, Ethiopia; ${ }^{4}$ Assistant Professor of Internal Medicine, School of Medicine, College of Health Sciences and Referral Hospital Aksum University, Aksum, Ethiopia; ${ }^{5}$ Lecturer of Pediatric and Child Health Nursing, Department of Nursing, College of Medicine and Health Science, University of Gondar, Gondar, Ethiopia; ${ }^{6}$ Assistant Professor of Physiotherapy, Department of Physiotherapy, College of Health Sciences, Mekelle University, Mekelle, Ethiopia; ${ }^{7} \mathrm{MSc}$ in Physiology Department of Biomedical Sciences, College of Health Sciences and Referral Hospital Aksum University, Aksum, Ethiopia; ${ }^{8} \mathrm{MSc}$ in General Public Health HIV \& SRH Directorate, Aksum University, Ethiopia.

Corresponding Author: Hafte Teklay, Aksum, Tigray, Ethiopia, Condominium University road, P. O. Box: 298; Email: haftishkind@gmail.com

Received: 19 August 2017

Accepted: 03 October 2017

Published: 10 January 2018 the Ponseti method which is better for success rate and the outcome is affected by many factors. Early diagnosis and treatment should be the main paradigms to decrease the risk of physical disability due to clubfoot. The study was aimed at assessing the practice of management and its outcome. Methods: Facility based retrospective medical record assessment was carried out. The retrieved and qualified data was entered into statistical package for the social sciences for analysis and then output is described and discussed. Results: The basic Ponseti principles and guidelines were practiced in Mekelle hospital considering some limitations. Physiotherapists were the health professionals who make all the clinical decision makings in the setup. The incidence of case relapse was $14.7 \%$, and the rate of tenotomy was $70.6 \%$. However, the facility scored overall success rate of $77.9 \%$. Conclusion: In Mekelle hospital, basic principles and guidelines of Ponseti method were practiced with some deviations. The rate of relapse and failure is also slightly higher. Deep social awareness about clubfoot management, grading the rate of tenotomy and reducing the treatment side effect is mandatory to achieve good outcome.

Keywords: Congenital clubfoot, Mekelle, Ponseti method, Treatment outcome

\section{How to cite this article}

Teklay H, Asmare Y, Kifle M, Abraha M, Baraki Z, Fissiha B, Hagos G, Gezehegn D. Treatment of congenital clubfoot and its outcome in Mekelle hospital, Tigray, Ethiopia. Edorium J Disabil Rehabil 2018;4:17. 


\section{EDORiUM Journals}

Edorium J Disabil Rehabil 2018;4:1-7.

Teklay et al.

Article ID: 100035Do5HT2018

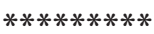

doi: 10.5348/Do5-2018-35-OA-1

\section{INTRODUCTION}

Congenital clubfoot (CCF) is one of the common congenital anomalies occurring around the ankle, subtalar, mid tarsal joints which is characterized by fore foot adducted (inward deviated), the whole foot is inverted (twisted inward) and the ankle is plantar flexed. They are inversion at subtalar joint, total hind foot adduction at talonavicular joint and equinus and varus at the ankle joint that is, a plantar flexed position, making the foot tend towards toe walking [1]. The three talar bones (calcaneus, cuboid and navicular) are rotated medially and are held in place by nearby tendons and ligaments. Soft tissues on the medial aspect of foot, calf and peroneal muscles are underdeveloped [2]. There are also evidences regarding the loss of soft tissue consistency, bone and joint impairments related primarily to talus in which its angle of inclination is decreased [3].

Humans started to understand congenital clubfoot as early as $400 \mathrm{BC}$ by the period of Hippocrates and Egyptian hieroglyphics. Hippocrates stated "Manipulate the foot as if holding a wax model, not by force, but gently" and advised the application of bandages for treatment. Nowadays the use of casting and bracing is becoming modern management method which reduces the need for surgery and rate of recurrences. Despite no one is sure about its etiology, there are many studies conducted so far describing that there its strong relationship with genetics; uterine mechanical forces and positional interaction of prenatal life [4]. It is associated again with an extrinsic factor keeping the deformity position that leads to muscle growth deficit. Clubfoot may be the only defect presented (isolated clubfoot) or may occur with other congenital anomalies (complex clubfoot). It could be also either postural or structural talipes equinovarus [3, 5].

The incidence of congenital clubfoot worldwide is estimated to be 1 to 4.5 per 1,000 live births but it varies among different races, settlement areas and sex. Most studies show a male to female ratio of $2: 1$ with about $50 \%$ of the cases being bilateral. In cases of unilateral clubfoot the right side affectation dominates. A positive family history has been associated to high incidence [4].

The problem born in mind is the extent to which our health professionals and society are ready to identify the case and how is the treatment afforded currently [6]. There are about 200,000 children born with clubfoot every year worldwide, where $80 \%$ of them are in the low and middle income countries. Global Clubfoot Initiative report in 2013 revealed that 21,515 clubfoot children were treated so far. Global Clubfoot Initiative report in 2013 revealed that 21,515 clubfoot children were treated so far. If it is left untreated at a young age of children, walking on the top or sides of the foot cause suffer from significant physical disability. Clubfoot deformity causes pain, difficulty in walking and inability to wear normal shoes $[7,8]$.

Out of all the cases of clubfoot worldwide every year it is estimated that $80 \%$ of children with clubfoot are born in developing countries in which less than $10 \%$ of resources are allocated for its care. It is highly prevalent in developing countries; for example 3-5\% more prevalent in Nigerian population which is half populous than that of USA [9].

In most countries, children with clubfoot get less access for attending school and often face stigma and social exclusion. Congenital talipes equinovarus is the cause of physical disability and impairment for different reasons; of which newly born babies are not well inspected for birth defects or congenital anomalies, those who are inspected and early diagnosed are not sent for health institutions to be treated rather they are ignored after trying with some traditional means like faith healing and holy water. The anomaly has high rate of recurrence once it is treated, family of the victim can also develop hopelessness because the procedure of correction needs long time so can stop to bring the child to the setting or there may not be equipped set up nearby [6-9].

Clubfoot makes the victim less sociable, feel ashamed of his/her disease, ignored by the community and family. Individuals with such cases are sent for holy schools rather than motivating for education. They are considered as not part of the society equally likely to contribute for the country specifically and the world at large [9].

The study would establish a baseline for others to conduct further studies as very limited or no available studies are conducted so far in our country. This work could ensure that it is nothing to know about the basic scientific details; rather the anatomical knowledge must be changed into a way it solves the problem of the society. It is assumed that it let's stakeholders to pay attention to reduce physical disability and maximize quality of life of those who need. So this study is aimed at assessing clubfoot management profile and its treatment outcomes.

\section{MATERIALS AND METHODS}

\section{Study design}

A facility based retrospective medical record assessment was conducted in Mekelle hospital among all patients who started treatment since 2011. 


\section{Sampling and sample size}

All patients who started treatment in 2011 at Mekelle hospital with complete documentation are included in the study. The patient's registration number is taken from a copy of report sent to cure clubfoot Ethiopia which is placed in the clinic. Having this, the patient's medical chart is searched in the chart room. The chart with the required year is considered and checked for inclusion in the study.

\section{Exclusion criteria}

- Clubfoot patients with incomplete documentation

- Those who are not yet discharged from the treatment follow-up

\section{Operational definition}

Cured: Clubfoot is said to be cured if the patient obtains cosmetically acceptable, pliable, functional, painless, plantigrade foot with Pirani score one and below (o) and not cured otherwise (1) [10].

\section{Data collection tools and procedures}

Complete checklist and questionnaire were adopted from similar literatures modified based on the study context and as if it is convenient to collect the data from existing source. Families of the patient were involved for further information and to complete data lost from the existing source through their contacts. Two data collectors from Ayder Referral Hospital physiotherapy clinic were involved under close supervision by the investigators and questions regarding the study were clarified. Two chart room workers were involved to collect the charts from the store.

\section{Data quality control}

Check list was properly designed and data collectors were well supervised by the investigators to ensure the data quality. The data collectors were trained for one day and they conducted pre-test to ensure that they are clear with the techniques how to gather the data. Every data sheet was checked and evaluated after collection for its completeness.

\section{Data processing and analyzing}

All the lists and questions were coded and entered into SPSS version 20 software package. After entering the data, frequencies and percentages were calculated to all variables which were found to be related with the objectives of the study.

\section{Ethical consideration}

Ethical clearance was obtained and formal institution based letter was sent to Mekelle hospital for seeking cooperation and accordingly permission was obtained for the data collection. The data extracted from medical registration chart is only for the purpose of the study and every data is kept confidential by securing personal information in passwords, and name of patients was not considered at all.

\section{RESULTS}

\section{Sociodemographical characteristics}

Mekelle hospital physiotherapy clinic has registered 402 clubfoot patients since 2009. Ninety-two (23\%) of them were registered for treatment since 2011. Twentyfour clubfoot patients were excluded from the study for meeting the exclusion criteria. Of the total study subjects $63.2 \%$ were males and the rest were females, which is near to 2:1 male to female ratio. Most of the clubfoot patients $(60.3 \%)$ were urban residents and all others were from rural areas. Majority of the study subjects (69.1\%) distance from the facility was $70 \mathrm{~km}$ and less. The age of 45 patients was four months and below. The mean age of the children with clubfoot at the initial presentation was $1.62 \pm$ (0.898) months (Table 1).

\section{Clubfoot management}

In Mekelle hospital, clubfoot is managed in physiotherapy clinic on separated room from other patients. Physiotherapists are still the one who was responsible for assessing, appointing, casting and the overall management of clubfoot and one surgeon for performing tenotomy. The physiotherapists started the management with complete assessment on printed out format then continue for clinical judgments. They then educate parents for treatment technique and its compliances.

The clubfoot management primarily is based on the basic Ponseti principles. Patients are either casted or appointed based on the parents' acceptability and stability after careful education about the technique at their first visit. Casting continues once a week till the physiotherapist decides the need for tenotomy or bracing. They apply the cast for the first, second, third, etc. visits to correct cavus, adductus and varus at variable number of casts according to the severity of the deformed position. Equinus is the last component of the deformity to be corrected with tenotomy or casting only. Tenotomy was conducted in the casting room by a single surgeon. Post tenotomy POP cast is applied for three weeks to ensure healing of the Achilles tendon.

Once casting is finished, the patients are transferred to 


\section{EDORIUM Journals}

Edorium J Disabil Rehabil 2018;4:1-7.

www.edoriumjournals.com/ej/dr

bracing or maintenance phase. Braces are prepared in the hospital by one technician. Parents are appointed to come two weeks after the first brace to check for compliances. The follow-up continues until the child starts to walk and get skeletal maturation. The appointments vary from 3-6 months and one year depending on the correction of the deformity.

\section{Clinical characteristics}

Congenital talipes equinovarus was bilateral in 45 (66.2\%) patients, right sided affection in 15 (22.1\%) patients and left sided affection in $8(11.8 \%)$ patients. The patients' initial severity measured at the time they first visited the clinic was grade III $75 \%$ patients and grade II for the other $25 \%$ of the patients on Pirani severity scoring scale. The total mean score at initial presentation of severity was 5.25 ( \pm 0.9122$)$. No clubfeet is recorded as grade I (Table 2).

Sixty-two patients (91.2\%) were free of other concomitant defects (isolated clubfoot) except a few patients were with some additional malformation. The common defects presented on the $6(8.8 \%)$ patients were joint complication (three patients), spinal (two patients) and cardiovascular system (one patient) defects in their respective order (Figure 1). Forty-eight (70.6\%) patients need Achilles tenotomy to release tendo-Achilles tendon to ensure the equinus is corrected. The patients on whom tenotomy was performed were 34 bilateral and 14 unilateral cases.

Foot anatomy was recovered with the use of repeated application of above knee serial casts (POP) in 12 patients but 41 of the cured children were corrected by casting and tenotomy. The relapse of the case was evident in 10 patients of which five children were non-operated (1:1). Eight patients were bilateral clubfoot and both feet were relapsed. The other two patients were unilateral right sided deformed children. Of the total relapsed cases, the components of the deformity that were recurred were equinus and cavus in four patients, only equinus reoccurred in other four patients and two patients were suffered from recurrence of cavus only. Half of the patients who have had relapse enter into another phase of treatment and the other half stopped the treatment.

The overall cure outcome on 68 clubfoot patients (113 feet) is $53(77.9 \%)$. Of these (cured), the largest proportion (32) had undergone tenotomy. The success rate for grade II and III patients was $88.24 \%$ and $74.52 \%$ respectively.

The number of casts required was significantly higher

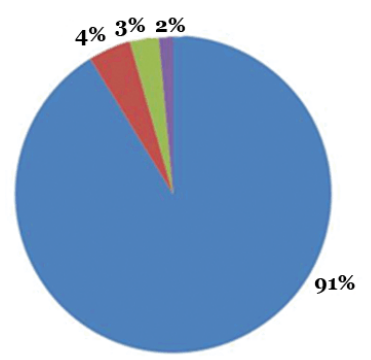

- Isolated clubfoot

- Joint complication

E Spinal disorder

- Cardiovascular system disorder

Figure 1: Distribution of clubfoot based on the presence of additional malformations $(\mathrm{n}=68)$

Table 1: Distribution of sociodemographic characteristics of cure and non-cured clubfoot patients' treatment in Mekelle hospital

\begin{tabular}{|c|c|c|c|c|}
\hline \multirow[t]{2}{*}{ Variables } & \multirow[t]{2}{*}{ Category } & \multicolumn{2}{|c|}{ Outcome } & \multirow{2}{*}{ Total N (\%) } \\
\hline & & Cured (1) & Not cured (o) & \\
\hline \multicolumn{5}{|l|}{ Sex } \\
\hline & Male & $33(62.3 \%)$ & $10(66.7 \%)$ & $43(63.23 \%)$ \\
\hline & Female & $20(37.7 \%)$ & $5(33.3 \%)$ & $25(36.76 \%)$ \\
\hline \multicolumn{5}{|l|}{ Residence } \\
\hline & Urban & $33(62.3 \%)$ & $8(53 \cdot 3 \%)$ & $41(60.3 \%)$ \\
\hline & Rural & $20(37.7 \%)$ & $7(46.7 \%)$ & $27(39.7 \%)$ \\
\hline \multicolumn{5}{|l|}{ Religion } \\
\hline & Christians & $47(88.7 \%)$ & $15(100 \%)$ & $62(91.2 \%)$ \\
\hline & Muslims & $6(11.3 \%)$ & o $(0.0 \%)$ & $6(8.8 \%)$ \\
\hline \multicolumn{5}{|l|}{ Age } \\
\hline & $\leq 4$ months & $37(69.8 \%)$ & $8(53 \cdot 3 \%)$ & $45(66.2 \%)$ \\
\hline & 4-8 months & $2(3.8 \%)$ & $2(13.3 \%)$ & $4(5 \cdot 9 \%)$ \\
\hline & $\geq 8$ months & $14(26.4 \%)$ & $5(33 \cdot 3 \%)$ & $19(27.9 \%)$ \\
\hline \multicolumn{5}{|c|}{ Distance from the facility } \\
\hline & $\leq 70 \mathrm{Km}$ & $40(75.5 \%)$ & $7(46.7 \%)$ & $47(69.1 \%)$ \\
\hline & 71-140 Km & $7(13.2 \%)$ & $5(33.3 \%)$ & $12(17.6 \%)$ \\
\hline & $\geq 141 \mathrm{Km}$ & $6(11.3 \%)$ & $3(20 \%)$ & $9(13.2 \%)$ \\
\hline
\end{tabular}




\section{EDORiUM Journals}

Edorium J Disabil Rehabil 2018;4:1-7.

Teklay et al. 5

www.edoriumjournals.com/ej/dr

Table 2: Sixty-eight patients populations from Mekelle hospital categorized by their sex-laterality clubfoot pattern

\begin{tabular}{llcccc}
\multicolumn{5}{c}{ Initial severity in Pirani severity scoring system } \\
\hline \multirow{3}{*}{ Defect pattern } & Bilateral & Grade II & Grade III & Total \\
& Right & 6 & 39 & 45 \\
& Left & 8 & 7 & 15 \\
& Total & 3 & 5 & 8 \\
\hline
\end{tabular}

for those who need tenotomy. Out of 82 feet measured to be 5.0 and above on Pirani severity scoring scale at initial presentation, 60 feet $(74.4 \%)$ required tenotomy but of the 31 clubfeet who were less than or equal to 4.5 on the Pirani severity scoring scale, only 22 (45.16\%) feet were referred to surgeon for tenotomy and 9 (54.83\%) did not.

\section{DISCUSSION}

The clubfoot patients' clinical history and profile is well documented relatively in the hospital. But it is questionable on the process of measuring the severity for its accuracy. Of course there is a discrepancy among professional and even in a repeated measurement of single personnel, however, here all subjects have exactly alike on their severity value on both sides in case of bilateral cases. This contradicts with a number of studies conducted $[6,11]$.

For non-cured bilateral, it was seen on both feet that is there were no cases such that they were with bilateral clubfoot and one cured and the other failed. This was also true for the distribution of tenotomies in which no tenotomy was done on one foot. This was not supported by study conducted in India and England. In general, the pattern and measurement of all the bilateral deformed patients had similar deformity, relapse, curative and Pirani scoring status unlike the study conducted in Southampton, England and India [11, 12]. This might be happened because, there is measurement inconsistency and unreliability among professionals, of wrong measurements leading to wrong decision making.

The overall success rate of the treatment in Mekelle hospital on 113 clubfeet is $77.9 \%$ which is lower than the findings of two studies conducted in India on 67 (89.29\%) and 53 (90.6\%) clubfeet but this is comparable with some other studies and manuals of the Ponseti method $(76.8-85 \%)[6,12]$. The result is more distant away from a Chinese research (96.92\% success rate) that was conducted to assess the effectiveness of Ponseti method [13]. This could be reasoned out as the studies were conducted by a different study design in addition to the low emphasis given to the disease and its management in our set up. The success rate of the patients cure varied with the severity such that it reduces with increasing the grade of severity on Pirani severity scoring system.

Even though the clubfoot clinic uses the principles of clubfoot treatment set by Dr. Ignacio Ponseti, there were some deviations from the studies conducted across the world in some way. But treatment timeline, approach to the parents and the overall management protocol was similar to the Ponseti method [14]. This might be because of the indispensable awareness and training provided by CCE to the physiotherapists throughout the country.

This study assured that $70.6 \%$ of the total subjects were referred for tenotomy and the procedure was conducted necessarily on both sides for bilateral cases. It was congruent with a study conducted in the US, New York [15-17] but in the case of the application of tenotomy in relation to laterality this study is exactly alike on both sides for all the patients unlike other studies [12] which reported differently for different patients in the sample that could be because of the interpersonal clinical decision making variation. A number of studies from America and Portugal also revealed that tenotomy is indicated in more than $80 \%$ of the cases presented $[15,18-19]$. This could be happened because the equinus deformity is the very resistant that is corrected last and tenotomy provides an additional $20-25^{\circ}$ of dorsiflexion.

Treatment complications include sore, ulcers, swellings, abrasions, bleeding and delayed healing of any type of surgical procedure. However, it was not explained which specific complication was evident on the source of the data. There were fewer patients cured who had different treatment complication. Such results were reported from different literatures showing that major of their conclusion was it delays, obscures, completely miss the anticipated outcome $[20,21]$. This explained by the fact that there is no question that additional surgical and medical conditions cause the problem to be aggravated and it reduces the application further manipulation, casts and braces by creating pain on the victim.

\section{Strengths and limitations of the study}

Strengths: The maximum possible trial is made to include all necessary variables from the existing data. This work showed the status the hospital regarding its clinical service for such neglected diseases, as health agenda in the developing nations is exclusively related to infectious 
disease.

Limitations: There are no local studies conducted for comparison and discussion. The facility did not utilize a constant patient assessment format which leads to poor quality of registration and reporting that is why 24 charts were excluded from the study.

\section{CONCLUSION}

The basic clinical characteristics of the congenital anomaly have fitted with different epidemiological reports. Even though there are little deviations from the actual guide line, general speaking Mekelle hospital practiced the Ponseti management. The management has achieved a success rate that is slightly lower than which is expected.

\section{REFERENCES}

1. Staheli L. Clubfoot: Ponseti Management. 3ed. USA: Global HELP Organization; 2009.

2. Drvaric DM, Kuivila TE, Roberts JM. Congenital clubfoot. Etiology, pathoanatomy, pathogenesis, and the changing spectrum of early management. The Orthop Clin North Am 1989 Oct;20(4):641-7.

3. Lochmiller C, Johnston D, Scott A, Risman M, Hecht JT. Genetic epidemiology study of idiopathic talipes equinovarus. Am J Med Genet 1998 Sep 1;79(2):906.

4. Miedzybrodzka Z. Congenital talipes equinovarus (clubfoot): A disorder of the foot but not the hand. $J$ Anat 2003 Jan;202(1):37-42.

5. Wynne-Davies R. Family studies and the cause of congenital club foot: Talipes equinovarus, talipes calcaneo-valgus and metatarsus varus. J Bone Joint Surg Br 1964 Aug;46:445-63.

6. Biruk WL. Management of clubfoot at Tikur Anbessa Hospital; Addis Ababa, Ethiopia. East and Central African Journal of Surgery 2007;12(1):24-9.

7. Initiative GC. Global clubfoot repot. 2013. 2014. [Available at: http://globalclubfoot.com/wp-content/ uploads/downloads/2015/07/Global-data-report2013-WEBSITE-DOWNLOAD.pdf]

8. Morcuende JA. Congenital idiopathic clubfoot: Prevention of late deformity and disability by conservative treatment with the Ponseti technique. Pediatr Ann 2006 Feb;35(2):128-30, 132-6.

9. Akintayo OA, Adegbehingbe O, Cook T, Morcuende JA. Initial program evaluation of the Ponseti method in Nigeria. Iowa Orthop J 2012;32:141-9.

10. Jain P, Mehtani A, Goel M, Jain S, Sood A, Kumar Jain A. Correlation of foot bimalleolar angle with Pirani score to assess the severity of congenital talipes equinovarus deformity. J Pediatr Orthop B 2012 Jan;21(1):68-72.

11. Porecha MM, Parmar DS, Chavda HR. Mid-term results of Ponseti method for the treatment of congenital idiopathic clubfoot: (A study of 67 clubfeet with mean five year follow-up). J Orthop Surg Res 2011 Jan 12;6:3.

12. Goriainov V, Judd J, Uglow M. Does the Pirani score predict relapse in clubfoot? J Child Orthop 2010 Oct;4(5):439-44.

13. Wang YZ, Wang XW, Zhang P, Wang XS. Application of Ponseti method in patients older than 6 months with congenital talipes equinovarus. Beijing Da Xue Xue Bao Yi Xue Ban 2009 Aug 18;41(4):452-5.

14. Lohan I. Treatment of Congenital Clubfoot Using the Ponseti Method. Seattle, USA: Global HELP Organization; 2011.

15. Lebel E, Karasik M, Bernstein-Weyel M, Mishukov Y, Peyser A. Achilles tenotomy as an office procedure: Safety and efficacy as part of the Ponseti serial casting protocol for clubfoot. J Pediatr Orthop 2012 Jun;32(4):412-5.

16. Richards BS, Faulks S, Rathjen KE, Karol LA, Johnston CE, Jones SA. A comparison of two nonoperative methods of idiopathic clubfoot correction: The Ponseti method and the French functional (physiotherapy) method. J Bone Joint Surg Am 2008 Nov;90(11):2313-21.

17. Scher DM, Feldman DS, van Bosse HJ, Sala DA, Lehman WB. Predicting the need for tenotomy in the Ponseti method for correction of clubfeet. J Pediatr Orthop 2004 Jul-Aug;24(4):349-52.

18. Alves C, Escalda C, Fernandes P, Tavares D, Neves MC. Ponseti method: Does age at the beginning of treatment make a difference? Clin Orthop Relat Res 2009 May;467(5):1271-7.

19. Dobbs MB, Rudzki JR, Purcell DB, Walton T, Porter KR, Gurnett CA. Factors predictive of outcome after use of the Ponseti method for the treatment of idiopathic clubfeet. J Bone Joint Surg Am 2004 Jan;86-A(1):22-7.

20. Adegbehingbe OO, Oginni LM, Ogundele OJ, Ariyibi AL, Abiola PO, Ojo OD. Ponseti clubfoot management: Changing surgical trends in Nigeria. Iowa Orthop J 2010;30:7-14.

21. Pavone V, Testa G, Costarella L, Pavone P, Sessa G. Congenital idiopathic talipes equinovarus: An evaluation in infants treated by the Ponseti method. Eur Rev Med Pharmacol Sci 2013;17(9):2675-9.

$* * * * * * * * *$

\section{Acknowledgements}

Our acknowledgement goes to the University of Gondar, college of medicine and health sciences, Mekelle hospital physiotherapy clinic workers, that this work would have been impossible without their cooperation. We are grateful for the valuable contribution of the bureau of road and transport, Aksum branch as it provided us the list of distance of each city from Mekelle.

\section{Author Contributions}




\section{EDORiUM Journals}

Edorium J Disabil Rehabil 2018;4:1-7.

www.edoriumjournals.com/ej/dr

Hafte Teklay - Substantial contributions to conception and design, Drafting the article, Final approval of the version to be published

Yared Asmare - Acquisition of data, Revising it critically for important intellectual content, Final approval of the version to be published

Manay Kifle - Acquisition of data, Analysis and interpretation of data, Revising it critically for important intellectual content, Final approval of the version to be published

Mebrahtom Abraha - Substantial contributions to conception and design, Drafting the article, Final approval of the version to be published

Zeray Baraki - Analysis and interpretation of data, Drafting the article, Final approval of the version to be published

Berihu Fissiha - Substantial contributions to conception and design, Revising it critically for important intellectual content, Final approval of the version to be published Gebremedhin Hagos - Substantial contributions to conception and design, Revising it critically for important intellectual content, Final approval of the version to be published

Dejen Gezehegn - Substantial contributions to conception and design, Analysis and interpretation of data, Revising it critically for important intellectual content, Final approval of the version to be published

\section{Guarantor of Submission}

The corresponding author is the guarantor of submission.

\section{Source of Support}

None

\section{Conflict of Interest}

Authors declare no conflict of interest.

\section{Copyright}

(C) 2018 Hafte Teklay et al. This article is distributed under the terms of Creative Commons Attribution License which permits unrestricted use, distribution and reproduction in any medium provided the original author(s) and original publisher are properly credited. Please see the copyright policy on the journal website for more information.
Access full text article on other devices

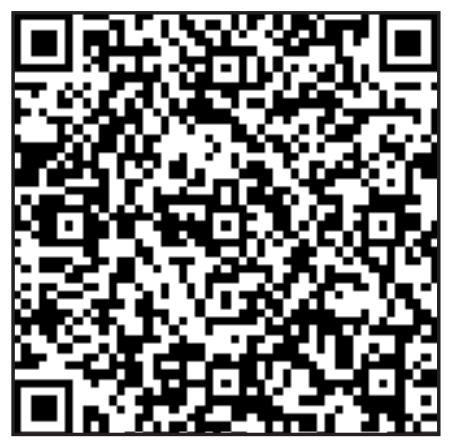

Access PDF of article on other devices

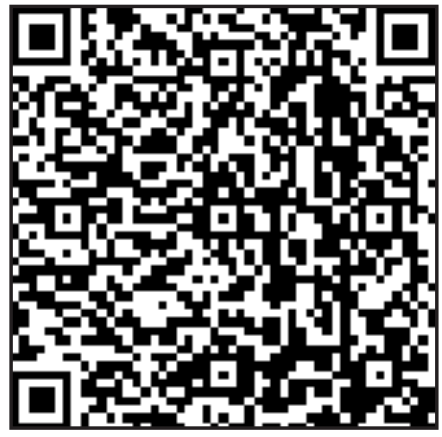

